\title{
Exploration and practice of innovative entrepreneurship training program in the management training base
}

\author{
Zhou Farong ${ }^{1, a}$, Zhang Yong Zhi ${ }^{2, b}$ \\ ${ }^{1}$ Chongqing University of Technology Economics Experimental Teaching Center Chongqing, China, 400067 \\ ${ }^{2}$ Economic Management Experimental Teaching Center Chongqing, China, 400067 \\ aE-mail: 853917491@qq.com \\ bE-mail: 1959475632@qq.com
}

Keywords: innovation and entrepreneurship training, role simulation, operation and entrepreneurship, resource intensive

\begin{abstract}
Relying on the management innovation and entrepreneurship training base to carry out the innovation and entrepreneurship training program is an important means to cultivate college students' innovative spirit and practical ability. Through interest-driven training project development, role-based introduction process training, business operation simulation, virtual network platform promotion, entrepreneurial resource intensive management, and promotion of training programs, etc., enhance the innovation ability of college students.
\end{abstract}

\section{Introduction}

According to the Ministry of Education, all colleges and universities implement the innovation and entrepreneurship training program for college students. Promote the transformation of educational ideas and concepts in higher education institutions, reform the talent training model, strengthen the training of college students' innovative and entrepreneurial ability, and enhance the innovative ability of college students [1].

\section{The problems and thinking of the innovative entrepreneurship training program}

Through the investigation and analysis of 300 teams and 5,000 students preparing participants, the following factors are mainly included

\subsection{Students' lack of awareness of participating in project training}

He school's innovation and entrepreneurship training program was launched at a shorter time, and students did not know enough about it. The college did not carry out relevant education, and did not recognize the importance of the cultivation of innovative ability and the training of entrepreneurial programs for their own development. The standard of the project is higher, resulting in a "fear" mentality. Leading some students to "stop and wait" [2].

\subsection{The tutor of the training program is not in place}

The survey found that the mentoring guidance in the entrepreneurial training program was not in place because many instructors were not teachers who specialized in entrepreneurship education and guidance, and lacked guidance experience. The school did not have a method of calculating the workload of the tutor. The teacher conducted the guidance labor but did not get the recognition. The school did not establish a mechanism for joint cultivation with off-campus units, and did not form an effective mechanism for combining a school tutor with a tutor with practical experience outside the school.

\subsection{A sound classification evaluation mechanism has not yet been established}

Lack of implementable classification assessment indicators and lack of scientific evaluation 
feedback mechanisms. Students participating in the training program are unclear about the assessment requirements and do not know how to do it; it is difficult for the guidance tutor to grasp the goal and content of the college students' innovation and entrepreneurship training program, which makes it difficult to control.

\subsection{Lack of a carrier for an innovative entrepreneurship training program}

The implementation of the Innovative Entrepreneurship Training Program must have a carrier of practice. At the school level, there is no effective management method for incorporating innovative entrepreneurship training programs into various carriers.

\section{The Innovation and Entrepreneurship Training Program on the Innovation and Entrepreneurship Training Base}

The economic management innovation and entrepreneurship training base covers three functional areas: entrepreneurship training zone, entrepreneurial combat zone, and entrepreneurial service zone. Relying on the establishment of a two-way integration of innovation and entrepreneurship platform as an important carrier of the management of entrepreneurship training programs.

\section{1 “Interest Driven” Innovation and Entrepreneurship Training Program}

1) Innovative entrepreneurship training program combined with professional guidance. The students' innovative entrepreneurship training program proposes multiple options according to their own interests; after the selection of entrepreneurial tutors, the main factors are professional (technical), market prospects, similar products, business models, cost accounting, financial risks, etc. [3]. In this way, the project has students' interest, professionalism and marketability, which is conducive to cultivating students' innovative thinking ability and practical operation ability.

2) Introducing risk mechanism and competition mechanism to mobilize teachers to guide innovation training programs. Encourage teachers to use scientific research projects as student innovation and entrepreneurship training programs, let students think about the literature, and come up with their own solutions for a certain project, discuss with the teachers, the teacher will affirm or point out the deficiencies, so repeatedly, eventually Putting practical and feasible solutions into practice, students' ability to solve problems and their ability to innovate and entrepreneurial skills will be greatly improved.

3) Encourage inter-professional training projects across grades. When the college students' innovation and entrepreneurship training project team is formed, they encourage teams of different professional backgrounds from different disciplines to form a team, break through the limitations of traditional disciplines and majors, set up project teams, and construct a research and innovation training mechanism for college students who are conducive to interdisciplinary research.

\section{2 "Role" to carry out the training of entrepreneurship training program}

1) Team integration training. Students form a team based on their interests and hobbies and certain rules. Training begins with a thorough understanding of the team members, forming a team culture, giving their team a name, designing their own team goals and training program implementation plan.

2) Learning and writing a business plan. According to the training program, prepare business plan, including product and service introduction, marketing, business model, company strategy, team composition, product cost accounting, operation mode Financial analysis and investment return and market exit mechanism.

3) Virtual registration company. According to the "Company law" base to provide virtual company registration, industrial and commercial inspection, tax registration, bank accounts, customs approval, talent introduction, Social security services, market supervision and other comprehensive training and services. 


\section{3 “Corporate Operation” simulation, implementation of innovative entrepreneurship training program}

1) Intensive training of business enterprise knowledge. The training content takes the whole process of entrepreneurship as the main thread, covering the enterprise creation plan, enterprise bid registration, enterprise start-up stage management and so on.

2) Simulating the "company" to establish management objectives. The participants in the process are mainly to improve the project's operation plan, the execution record, the project daily schedule, the participant number, the marketing plan, the profit situation, the financial statement, the project summary.

3) Simulation of "company" operation management. Simulate the operation of the enterprise, formulate the marketing strategy, analyze the competitor's management strategy, arrange the production plan, build the sales channel, analyze the enterprise Operation Financial report, Market Attestation, raise the fund, the cash flow through each index and the competitor's disparity.

\section{4 virtual platform - "come to start a business" to enhance the innovation and entrepreneurship training project}

1) Select the project and enter the virtual network platform .After the students selected the project, the students completed the role of Division, their respective duties.

2) Virtual "e-commerce" risk operation management. Verify your own entrepreneurial projects and run your own company. Related to human resources management, finance, marketing, procurement of practical training.

\section{Conclusions}

College students' innovation and entrepreneurship training program is an important link in the improvement of entrepreneurship education system in colleges and universities. It is the expansion and deepening of quality education. It is helpful to help college students understand entrepreneurship correctly and rationally, and cultivate the knowledge, ability and psychology needed for college students to succeed in business. The Innovative Entrepreneurship Training Program is a systematic project. Leaders attach importance to, plan for unity, linkage of relevant departments, and establishment of a clear organizational structure and operational mechanism are important guarantees for solid entrepreneurship education.

\section{References}

[1] Outline of National Medium- and Long-Term Education Reform and Development Plan (2010-2020).2010

[2] Ministry of Education. Notice of the Ministry of Education on the implementation of the "Undergraduate Teaching Project" national-level college students' innovation and entrepreneurship training program [Z]. Beijing, 2012: 1-1.

[3] Guo Li, Wang Wei, etc. Exploring the management mode of "College Students' Innovation and Entrepreneurship Training Program” [J], Modern Educational Technology 2012: (6- )

[4] Zhang Yongzhi. Innovation and Practice of Economic Management Class Entrepreneurship Training Platform—-Taking Chongqing Technology and Business University Entrepreneurship Training Platform as an Example [J].Western Forum 2014(1)12-14

[5] Wang Changpeng. Exploration and practice of innovation and entrepreneurship training for new undergraduate college students [J] China Electric Power Education 2014:20 